\title{
Bluff Body Impact on Harvested Heat Transfer from Heated Plate
}

\author{
Osama khorais ${ }^{\mathrm{a}}$ Mohamed Abdullah ${ }^{\mathrm{a}, \mathrm{b}}$ Kareem Emara $^{\mathrm{a}}$ \\ ${ }^{a}$ Department of Mechanical Power Engineering, Faculty of Engineering, Mattaria, Helwan University, P.O. Box 11718, Masaken El-Helmia, Cairo, Egypt \\ ${ }^{\text {b }}$ Zohr Field, Petrobel Company, almokhaim Aldaem ,Cairo ,Egypt
}

\begin{abstract}
Thermal energy management and developing a reliable heat transfer system are a major concern for engineering societies. The present work aimed to investigate numerically (by using ANSYS Fluent 19.) heat transfer behavior of conventional used bluff bodies on hot plate. The study made accredited change in geometry (circular, square and triangular bluff bodies). The study covered Reynolds number range $(2600<\operatorname{Re}<9000)$ based on the plate characteristic length, and various separation distance between the hot plate and bluff body. The Nusselt number is taken as an indicator of heat transfer interaction due to the previous parameter change. While best temperature performance was achieved for circular, square and triangular bluffs at second hot plate location $\left(\mathrm{P}_{2}\right)$ was $\mathrm{T}=326 \mathrm{~K}$ and $\mathrm{T}=329 \mathrm{~K}$ respectively Finally, Nusselt number enhancement achieved by this technique according to the base case (without bluff body) was $178 \%, 175 \%$ and $165.2 \%$ for triangular, square, and circular bluff body, respectively.
\end{abstract}

\section{Key Words}

Flat plate, heat transfer enhancement, wake flow and bluff body

\section{Nomenclature}

\begin{tabular}{|c|l|}
\hline \multicolumn{2}{|c|}{ Symbols } \\
\hline $\mathrm{A}_{\mathrm{S}}$ & Surface area of heated plate $\left(\mathrm{m}^{2}\right)$ \\
\hline$C_{p}$ & Specific heat of fluid $(\mathrm{J} / \mathrm{kg} \cdot \mathrm{K})$ \\
\hline $\mathrm{h}$ & Average heat transfer coefficient $\left(\mathrm{W} / \mathrm{m}^{2} \cdot \mathrm{K}\right)$ \\
\hline $\mathrm{L}_{\mathrm{h}}$ & Heated plate characteristics length $(\mathrm{m})$ \\
\hline $\mathrm{Nu}$ & Nusselt number \\
\hline $\mathrm{p}$ & Pressure $\left(\mathrm{N} / \mathrm{m}^{2}\right)$ \\
\hline $\mathrm{q}$ & Heat flux $\left(\mathrm{W} / \mathrm{m}^{2}\right)$ \\
\hline $\mathrm{Re}$ & Reynolds number \\
\hline $\mathrm{P}_{\mathrm{i}}$ & Dimensionless separation number \\
\hline $\mathrm{T}_{\mathrm{b}}$ & Fluid bulk temperature $(\mathrm{K})$ \\
\hline
\end{tabular}




\begin{tabular}{|c|l|}
\hline $\mathrm{T}_{\text {in }}$ & Inlet flow temperature $(\mathrm{K})$ \\
\hline $\mathrm{T}_{\text {out }}$ & Outlet flow temperature $(\mathrm{K})$ \\
\hline $\mathrm{T}_{\mathrm{s}}$ & Surface temperature of heated plate $(\mathrm{K})$ \\
\hline$u_{i}$ & Velocity vector $(\mathrm{m} / \mathrm{s})$ \\
\hline $\mathrm{V}$ & Flow inlet velocity $(\mathrm{m} / \mathrm{s})$ \\
\hline$\rho$ & Fluid density $\left(\mathrm{kg} / \mathrm{m}^{3}\right)$ \\
\hline$\lambda$ & Fluid thermal conductivity $(\mathrm{W} / \mathrm{m} . \mathrm{K})$ \\
\hline$\mu$ & Fluid dynamic viscosity $(\mathrm{kg} / \mathrm{m} . \mathrm{s})$ \\
\hline
\end{tabular}

\section{Introduction}

Behavior of fluid flow and heat transfer development techniques plays a vital role in many industrial applications, Such as heat exchangers, fuel premixing in combustion chamber and conventional solar air heater... etc. [1-3,6]. Heat transfer development techniques are divided into two major categories active technique and passive technique; active method require external power to preserve the enhancement mechanism, as vibration of surface and well stirring with mechanical aid. Whereas passive methods depend on increasing the exposed surface like fins which interact with working medium, or increasing exposure time with cooling fluid, by using rough surfaces and bluff bodies for example. Geometries of bluff body occupy a wide range of heat transfer enhancement research scope. By focusing on geometry circumferences, blockage ratio and fluid flow criteria (density, temperature, Reynolds number, etc.). the influence of semi-circular obstacle on forced heat convection and fluid behavior were numerically studied. While incidence angel used were $\left(0^{\circ} \geq \alpha \geq 180^{\circ}\right.$ ) and Reynolds number range (from $80^{\circ}$ to $180^{\circ}$ ). found that maximum streamline curvature observed at $180^{\circ}$ [4]. A Study aimed to raising solar energy performance by investigating delta obstacle shape influence installed on absorber surface of solar air heater. Also, considered the influence of incidence angel which ranged from $30^{\circ}$ to $90^{\circ}$, Reynolds number from 2100 to 30000 and change in obstacle height and longitudinal pitch. In order to thermo-hydraulic performance at the optimum design get a better value than previous works [5]. Equilateral triangular bluff heat transfer effect investigated in injected air by nano particles. The study considered the variation influence in triangle position (side and vertex facing flows), nano concentration (0:5\%) and Reynolds number in laminar flow (50 $\leq \operatorname{Re} \leq 200)$. Finally, side facing obstacle led to heat transfer performance greater than vertex facing [6]. Constructed three rectangular heaters in tandem at duct bottom used in thermal cooling investigation. A triangular bar located in three vertical positions with Reynolds number range from 400 to 1300 . Study found a progressive fluctuation in heat transfer due to bar position [7]. Square bluffs group arranged in triangle form to study the impact in convection heat transfer numerically. Transient and turbulent mediums and bluffs array order considered. Finally developed best ratios for total area of rectangles to the triangle formed area [8]. A collective experimental study held to compare between the most basic bluff bodies (triangle, circle, and rectangle) 
in thermal effect. The study took in count many parameters flow blockage ratio (9.33\%, 18.66\% and 28\%), Reynolds number $(2700 \leq \mathrm{Re} \leq 13000)$ and position angels $\left(0^{\circ},+45^{\circ}, 90^{\circ}\right.$ and, $\left.-45^{\circ}\right)$. Hot bar behind the obstacles in seven different axial places to find best thermal behavior. discovered that Reynolds number, obstacle shape, size, heated plate orientation angle of the object and its axial location had a main effect on heated plate cooling of in downstream region. Also defined relation between the consequence of plate angel on heat transfer rate inversely proportional to aspect ratio [9].

The present work, aimed to make a comparison study to build a numerical comparative model. The model aimed to save efforts for future study and make a comparison between the conventional bluff bodies influence on heat transfer development. bench test model contains air tunnel, hot plate with $3 \mathrm{~mm}$ height, and immovable bluff body of different geometries (circular, square and triangular shapes). Hot plate location is changeable for bluff body position. The changing distance termed dimensionless separation number $\left(\mathrm{P}_{\mathrm{i}}\right)$ where $1.81<\mathrm{P}<13.82$, also Reynolds number ranged from 2600 to 9000.

\section{Computational Method}

\subsection{Test Bench}

A duct of $1000 \mathrm{~mm}$ length and $150 \mathrm{~mm}$ height was used, which contained a bluff body with constant blockage ratio $18,66 \%$. The blockage ratio is the ratio of bluff height to the duct height. Hot plate has $14 \mathrm{~mm}$ x $3 \mathrm{~mm}$ cross-sectional area. plate was installed axially centered with maximum temperature $373 \mathrm{~K}$. bluff bodies positioned enterally in the duct. the hot plate location was changed from $\mathrm{P}_{1}$ to $\mathrm{P}_{7}$ as shown in Fig.1. Also, Reynolds number ranged from 2600 to 9000 used, for all geometries and positions.

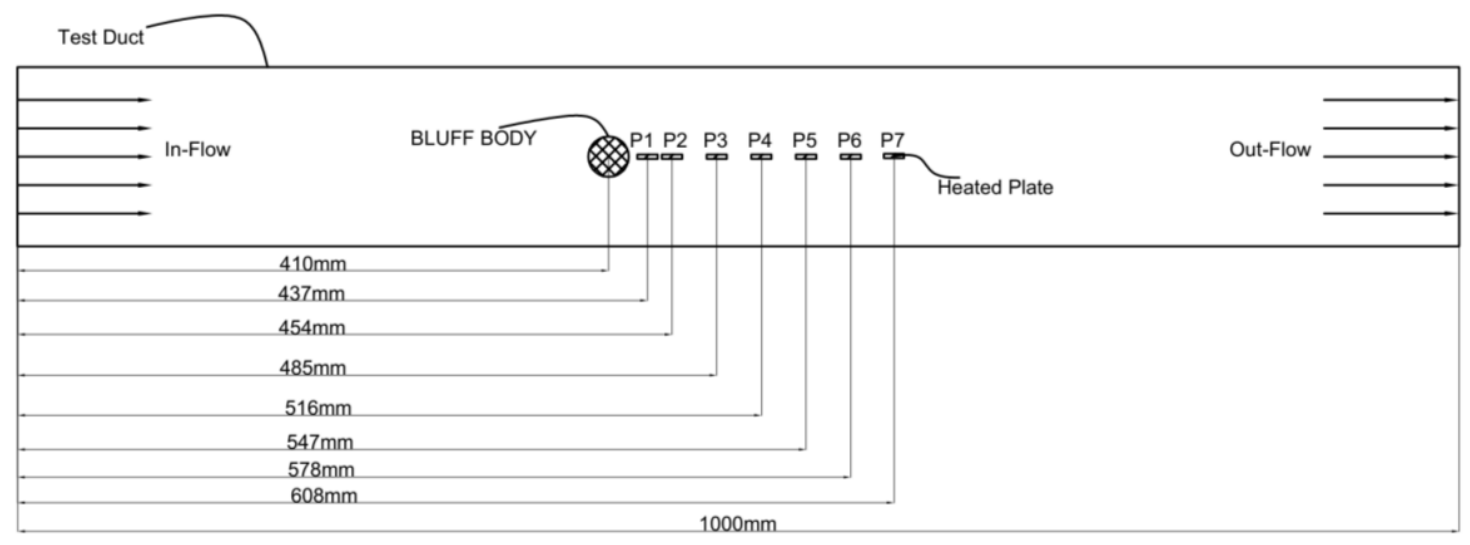

Fig.1: Modeled test bench components arrangement 


\subsubsection{Boundary conditions}

Boundary conditions accredited for flow entrance as uniform velocity at inlet (from $2 \mathrm{~m} / \mathrm{s}$ to $12.5 \mathrm{~m} / \mathrm{s}$ ) corresponding to Re number and $300 \mathrm{~K}$ temperature of flow, exit as outflow, walls for bluff bodies and adiabatic walls for duct walls, and temperature of hot plate is $373 \mathrm{~K}$.

\subsubsection{Bluff Body's Geometries}

Three conventional shapes used, square, triangular, and circular as shown Fig.2 with design length $24 \mathrm{~mm}$ which represent square side, triangle height and circle diameter [12]. Bluff locations was fixed while hot body position at different shapes along Reynolds number range.

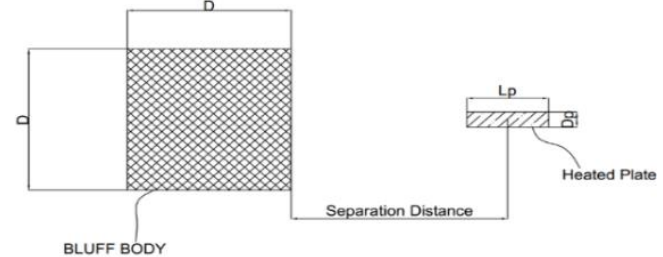

A: Set for square
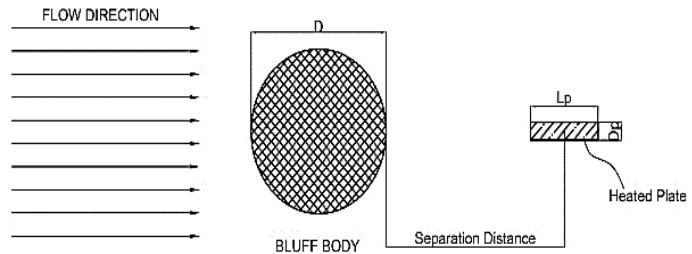

B: Set for circular

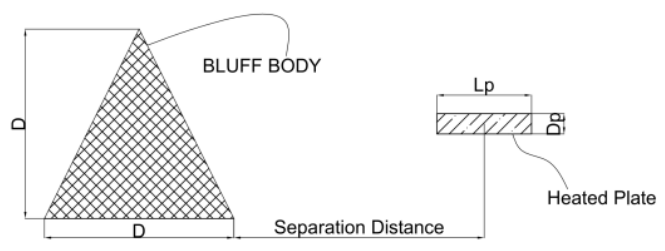

c: Set for triangular.

Fig.2: (A, B, \& C): Different bluffs test positioning

\subsection{Modeling and Simulation}

\subsubsection{Fluid Flow Governing Equations}

A numerical model for heat transfer and fluid was held. The most essential and most common use equations Continuity, momentum, energy, and heat transfer in test domain were solved using computational fluid dynamics (CFD) commercial code, ANSYS Fluent 19.0 as the following: -

The conservation of mass in cartesian coordinate system is given:

$\frac{\partial}{\partial \mathrm{x}_{i}}\left(\rho u_{i}\right)=0$

Where $(\rho)$ is air density $\left(\mathrm{kg} / \mathrm{m}^{3}\right)$ 
The Cartesian coordinate system for conservation of momentum equation given:

$\frac{\partial}{\partial x_{i}}\left(\rho u_{i} u_{j}\right)=-\frac{\partial p}{\partial x_{j}}+\frac{\partial}{\partial x_{i}}\left(\mu \frac{\partial u_{i}}{\partial x_{i}}\right)$

Energy equation

$\frac{\partial}{\partial x_{i}}\left(\rho C_{p} u_{i} T\right)=\frac{\partial}{\partial x_{i}}\left[(\lambda) \frac{\partial T}{\partial x_{i}}\right]$

Where $\mathrm{Cp}$ is the specific heat of fluid $(\mathrm{J} / \mathrm{kg} \cdot \mathrm{K}), \mathrm{T}$ is the flow temperature $(\mathrm{K})$ and $\lambda$ is the fluid thermal conductivity (W/m.K).

\subsubsection{The heat transfer equations}

The heat transfers computational model and fluid flow was developed under some assumptions. These assumptions are the following: -

- The flow is two dimensional, steady, incompressible, and turbulent flow.

- Neglecting the radiation heat transfer.

- The velocities $\mathrm{u}_{1}=\mathrm{u}_{2}=0$ at the walls where no slip boundary condition.

- Uniform inlet velocity.

the governing equations are processed by (FLUENT 19.0) using adopted doubleprecision solution and 2D approach. Also, second-order upwind scheme raised the simulation accuracy selected. correspondingly, all solutions converged by converging residual limit $10^{-6}$.

pressure "p", velocity components " $\mathrm{u}_{1}$ and $\mathrm{u}_{2}$ ", and temperature " $\mathrm{T}$ " in interior domain of the duct were solved. Besides, data post-processing, flow outlet temperature, centerline temperature, the surface heat flux and surface temperature were recorded. Both average heat transfer coefficient and average Nusselt number play the key role of this study, which is calculated as the following:

$\mathrm{Nu}=\frac{h \mathrm{~L}_{\mathrm{h}}}{\lambda}$

Where $L_{h}$ is hot body characteristics length $(0.014 \mathrm{~m}), \lambda$ is air thermal conductivity and $h$ is average heat transfer coefficient.

$\mathrm{h}=\frac{q}{\operatorname{As}\left(\mathrm{T}_{\mathrm{s}}-\mathrm{T}_{\mathrm{b}}\right)}$

Where $T_{b}$ is bulk temperature

$\mathrm{T}_{\mathrm{b}}=\frac{\mathrm{T}_{\text {in }}+\mathrm{T}_{\text {out }}}{2}$ 
Where q: heat flux $\left(\mathrm{W} / \mathrm{m}^{2}\right)$ represent the total rate of gained heat by air and

Reynolds number given by:

$R e=\frac{\rho \mathrm{VL}_{\mathrm{h}}}{\mu}$

\subsubsection{Numerical Methodology}

Current work used commercial package Ansys fluent 19.0 by double precision and coupled scheme. which develop robust and efficient single-phase operation for steady flows, also momentum second order upwind has better accomplishment compared to numerical stability and segregated solution.

\subsubsection{1 k- $\omega$ shear-stress transport (SST) model}

Two-equation eddy-viscosity model k- $\omega$ SST selected to simulate the turbulence, $\mathrm{k}-\omega$ formulation Capable of dealing with the behavior of flow at near-wall regions and can be used as Low-Re turbulence model without any extra damping functions. Formulation of shear stress transport (SST) combine the advantages of $\mathrm{k}-\omega$ addition to $\mathrm{k}-\varepsilon$ model stability at the far field. Moreover, handling a wide range of Reynolds numbers, is good at the near-wall behavior of the k- $\omega$ model and has the stability of the k- $\varepsilon$ model in the far field and the turbulence at inlet free-stream. It has a good behavior in adverse pressure gradients and separating flow. In addition, the SST k- $\omega$ model does produce a bit too large turbulence levels in regions with large normal strain, like stagnation regions and regions with strong acceleration. This tendency is much less pronounced than with a normal $\mathrm{k}-\varepsilon$ model though.

\section{Result and Discussion}

This study aimed to investigate heat transfer enhancement from hot plate positioned behind different bluffs (square, circular, and triangular) with moving the plate for certain positions. With a blockage ratio $18.6 \%$ and plate length 14 $\mathrm{mm}$. So, this study considered the effect of shape change, Reynolds number (which represent flow laminar, transient, and turbulent flow moods) and separation distance. the space between obstacles and test specimen called Dimensionless Separation distance $(\mathrm{P})$. it calculated as follow $\mathrm{P}=\mathrm{Da} / \mathrm{Dc}$, where $\mathrm{Da}$ is the axial distance between the heated plate and the bluff body center and Dc. represents the characteristic length of the heated body. consequently, the Nusselt change work as indicator for heat transfer performance.

\subsection{Impact of Changing Geometry}

This research includes mainly two different cases, used to cool the heated plate. The flow is directly flowing towards the heated body without any bluff body, In the first case, which is named the base case. The second case depends on using conventional shapes of bluff bodies, (triangular, square, and circular bluff bodies).to improve the 
heat transfer rate from the heated plate. The impact of geometry change shown clearly in Fig. 3 which clarify the distribution of fluid streamlines along all shapes.

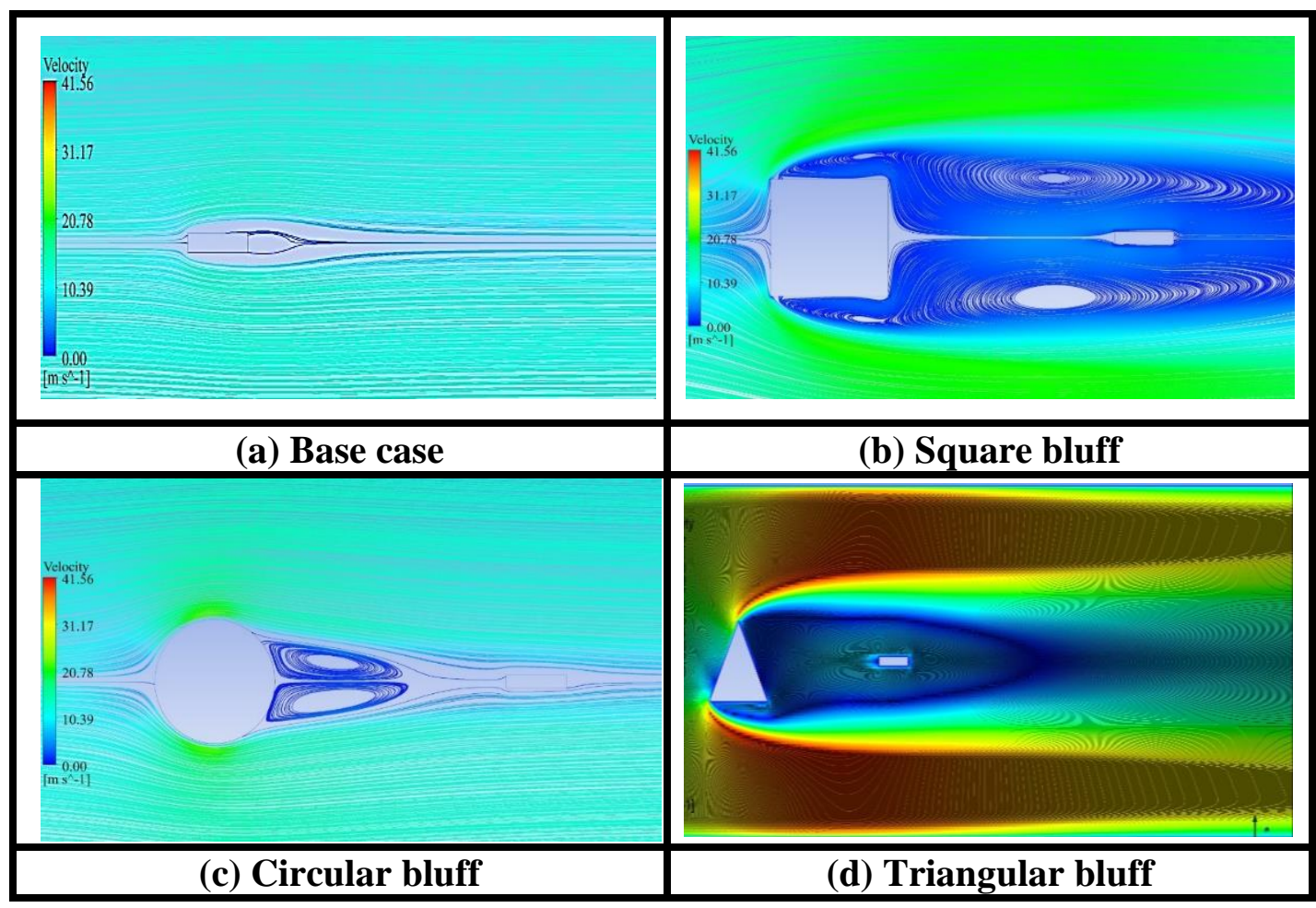

Fig.3: velocity streamline at highest velocity inflow $(12 \mathrm{~m} / \mathrm{s})$

at $P_{3}$ for all cases

\subsubsection{Smooth Duct}

Base case (without bluff body) used to measure and compare each change impact. Besides changing Reynolds number like sole changing parameter. Reynolds number change got Nusselt number enhancement close to $23 \%$ and found the linear relation between them Fig. 4 between using lowest and highest Reynolds number.

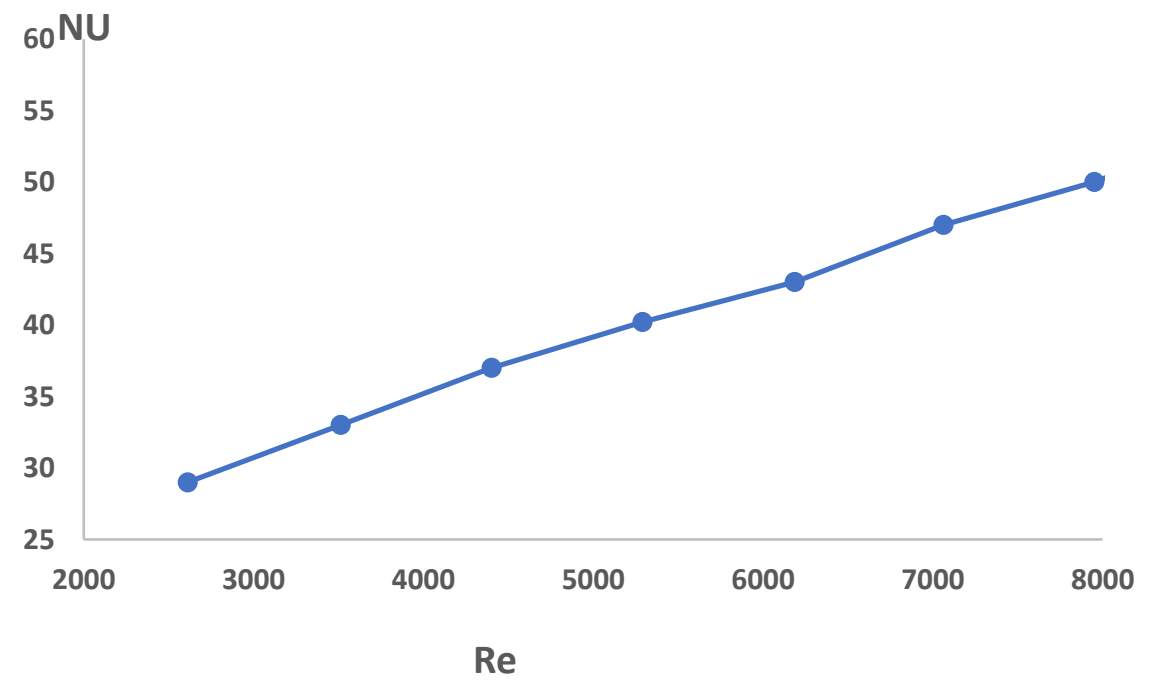

Fig.4: Re-Nusselt relation for no-bluff heat transfer impact with Reynold change 


\subsubsection{Second case (using bluff body)}

three conventional bluff bodies (circular, triangular and square) were used to improve the rate of heat transfer by increasing Nusselt number.

\section{Square Shape Effect}

By using square bluff body in order from $\mathrm{P}_{1}$ to $\mathrm{P}_{7}$ to find the best hot plate position which achieve highest Nusselt number. Results showed that, third location $\mathrm{P}_{3}$ accomplished $75 \%$ Nusselt number increasing over the base case (without using bluff body) at Reynolds number peak. It can be approximated to be linear. Fig.5 shows relation between Re number and $\mathrm{Nu}$ number.

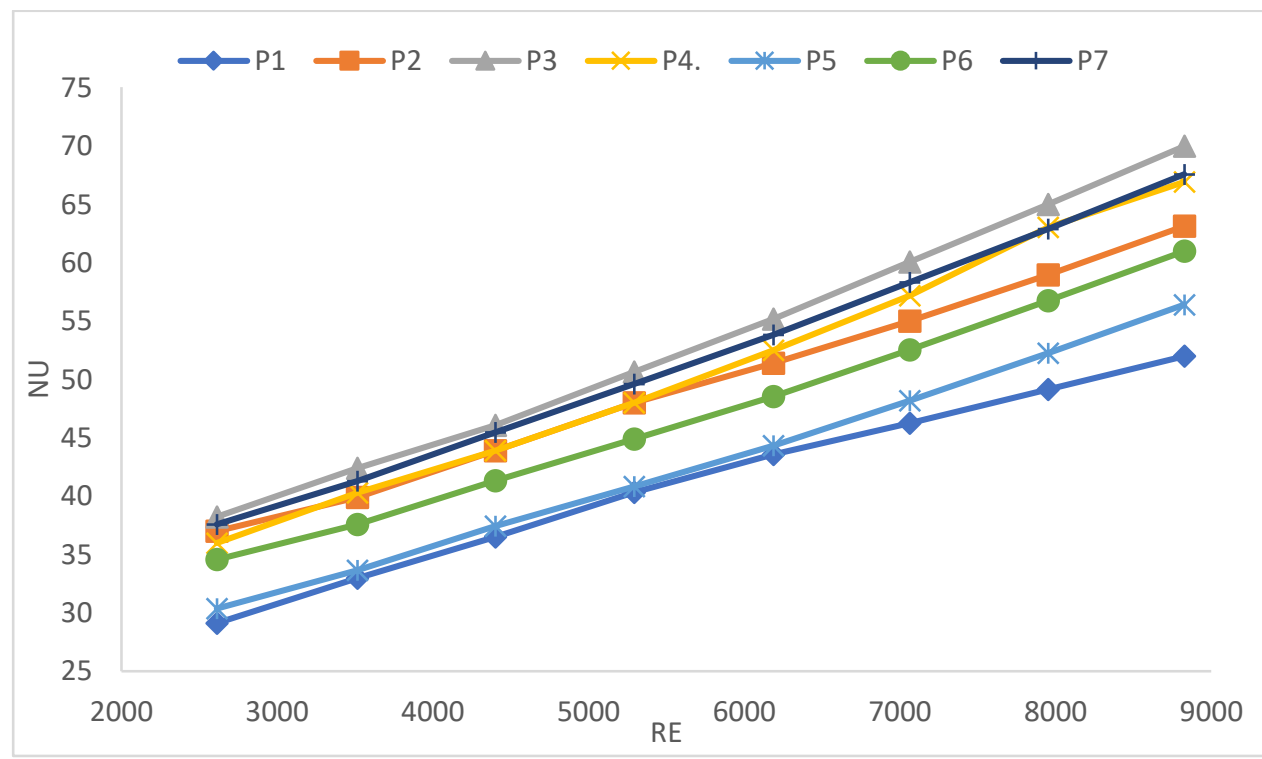

Fig.5: Comparison for Re-Nusselt at various positions for square bluff body

\section{Circular Shape Effect}

By using circular bluff body in order from $\mathrm{P}_{1}$ to $\mathrm{P}_{7}$ to find the best hot plate position which achieve heights Nusselt. Results showed that, third location $\mathrm{P}_{3}$ accomplished $65 \%$ Nusselt number increasing over the base case (without using bluff body) at Reynolds number peak. As shown Fig.6 shows the linear relation between Re number and Nu number. 


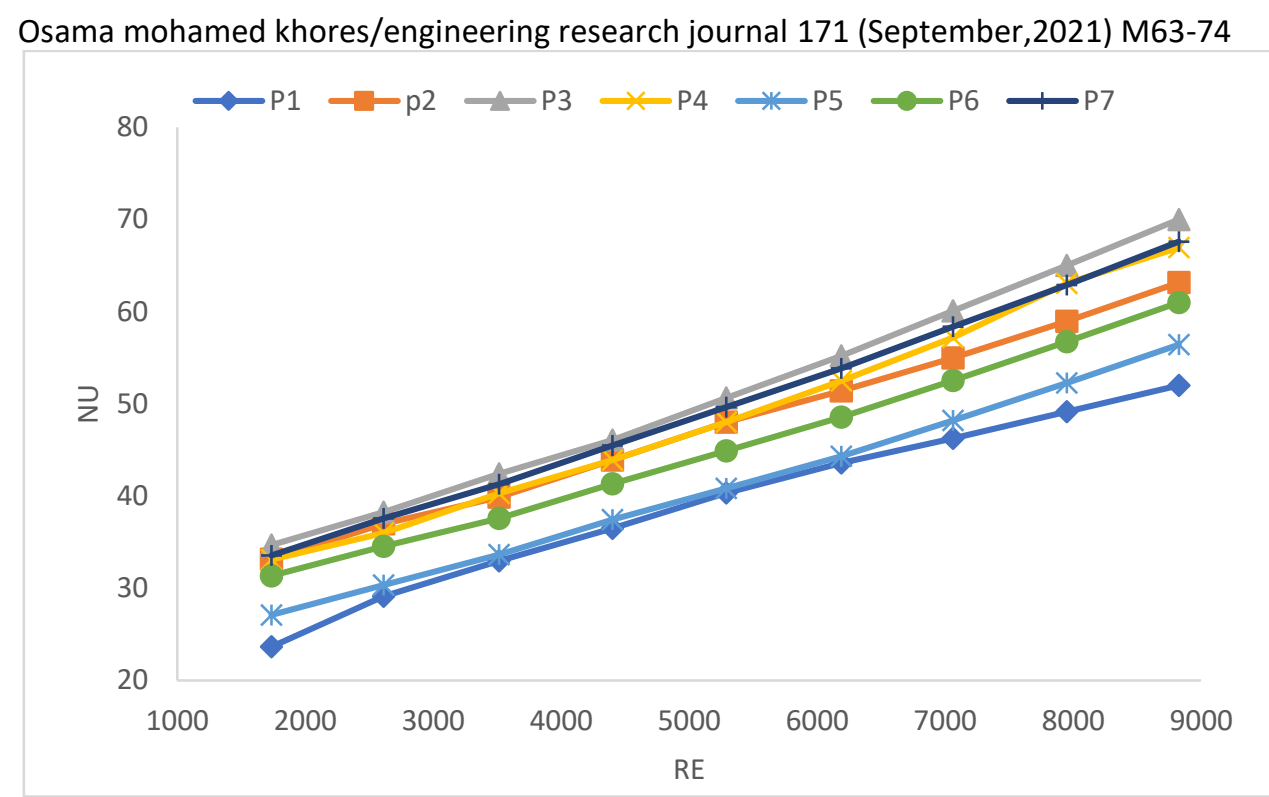

Fig.6: Comparison for Re-Nusselt at various positions for circular bluff body

\section{Triangular Shape Effect}

By using triangular bluff body in order from $\mathrm{P}_{1}$ to $\mathrm{P}_{7}$ to find the best hot plate position which achieve heights Nusselt. Results showed that, third location $\mathrm{P}_{3}$ accomplished $178 \%$ Nusselt number increasing over the base case (without using bluff body) at Reynolds number peak.

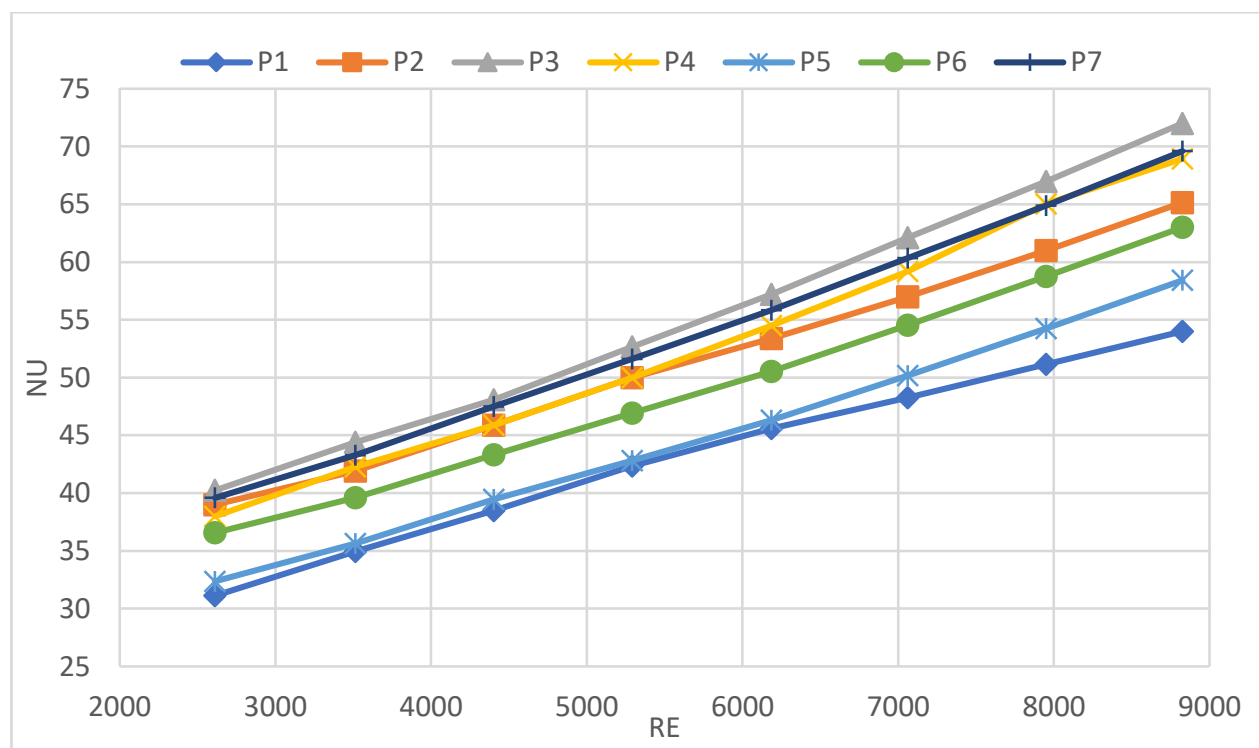

Fig.7: Comparison for Re-Nusselt at various positions for triangular bluff body

\subsection{Reynolds Number Influence}

Reynolds number act important role in our study which covered the three moods of flow laminar, transient, and turbulent. Reynolds number change with each bluff body develop different wake flow region parameters. subsequently heat transfer performance changes progressively directly proportional to Reynolds number. 
The best performance for bluff body (circular, square \& triangular) was at $\mathrm{P}_{3}$ better than base case (165.2\% for circular, $175 \%$ for square \& 178.75 for triangular).

\subsection{Separation Distance Change}

distance between bluff body nearest edge and center of heated plate (Fig.1) called Dimensionless Separation distance. Each case study held by fixing position with the whole Reynolds number range to examine best position in wake flow with all Reynolds number used. From the held study found that separation distances change had a significant effect on heat transfer performance. the best location for square, triangular, and circular bluff was at $\mathrm{P}_{3}$ location. and the heat extracted decreased gradually by increasing the separation distance. Fig.8 shows the variation of Nusselt number versus the different location of the heated plate for all bluff bodies at Reynolds number.

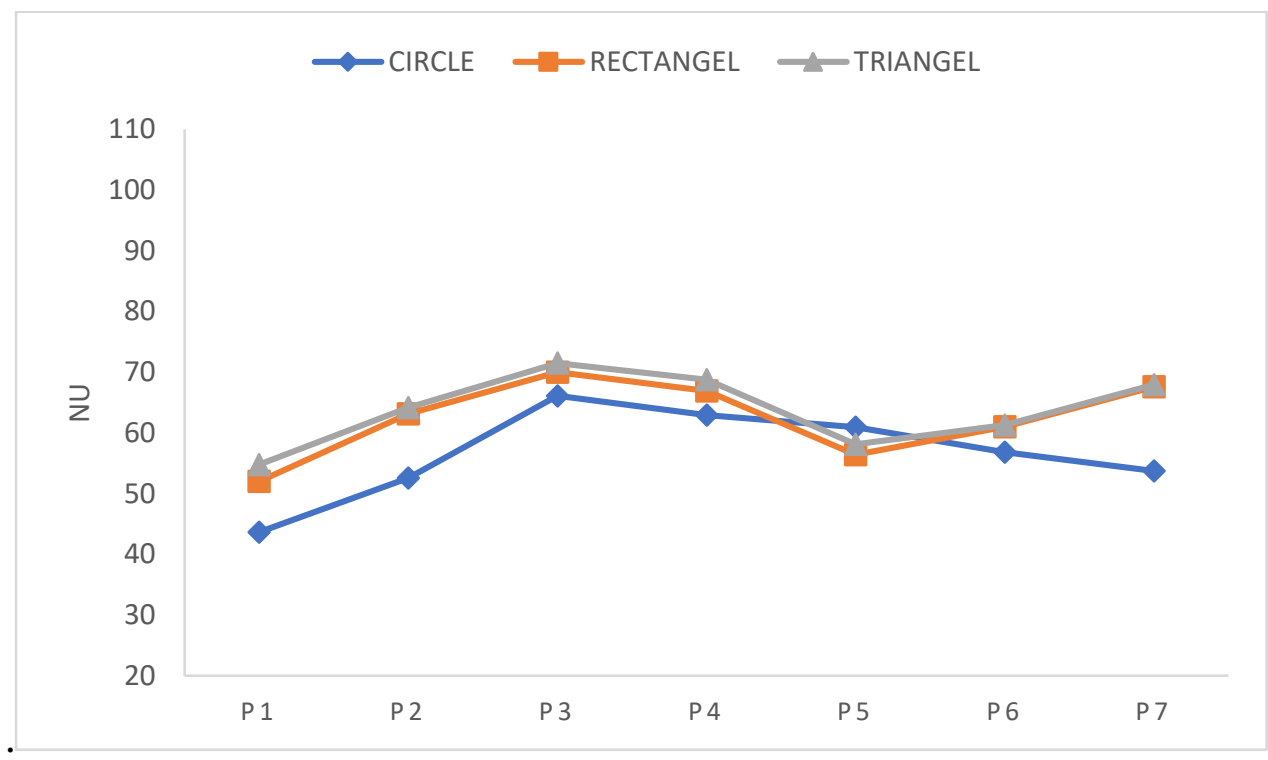

Fig.8: Nusselt number versus locations for all bluff bodies at $\mathrm{Re}=\mathbf{8 8 2 6}$

\section{Conclusion}

Present work aimed to compare the effected heat transfer extraction from hot plate located centrally in fluid flow field. Used geometries were triangle, circle and rectangle shape for bluff body and heated plate with $14 \mathrm{~mm} \times 3 \mathrm{~mm}$.

Study scope is monitoring and analyzing changing Reynolds number and positions influence on heat transfer for each case. Nusselt number used as guideline for heat transfer quality and leaded to following findings.

1- Using k- $\omega$ SST model is very useful for modeling the turbulence near wall region.

2- When fixing position and change in Reynolds number lead to change in Nusselt number proportionally. 
3- At fixed Reynolds number and different hot plate location, the Nusselt number swing according to position and found that best location is $\mathrm{P}_{3}$ for all cases. In addition, $\mathrm{P}_{3}$ had result better than $\mathrm{P}_{2}$.

4- Wake flow area created by circular and square bluffs tweaked the heat transfer to $(65: 70 \%)$ over the best practice achieved by base case at third position.

\section{References}

[1] Gaetti, M., R. Gaudron, C. Mirat, L. Zimmer, and T. Schuller. 2019. "Impact of Swirl and Bluff-Body on the Transfer Function of Premixed Flames." Proceedings of the Combustion Institute 37 (4): 5197-5204.

https://doi.org/10.1016/j.proci.2018.06.148.

[2] Wang, Lu Qing, Hong Hao Ma, Zhao Wu Shen, and Jun Pan. 2019. "Effects of Bluff Bodies on the Propagation Behaviors of Gaseous Detonation." Combustion and Flame 201: 118-28. https://doi.org/10.1016/j.combustflame.2018.12.018.

[3] Kusumi, Koji, Tomoaki Kunugi, Takehiko Yokomine, Zensaku Kawara, Jesus A. Hinojosa, Egemen Kolemen, Hantao Ji, and Erik Gilson. 2016. "Study on Thermal Mixing of Liquid-Metal Free-Surface Flow by Obstacles Installed at the Bottom of a Channel." Fusion Engineering and Design 109-111: 1193-98. https://doi.org/10.1016/j.fusengdes.2015.12.055.

[4] Pal Singh Bhinder, Amrit, Sandip Sarkar, and Amaresh Dalal. 2012. "Flow over and Forced Convection Heat Transfer around a Semi-Circular Cylinder at Incidence." International Journal of Heat and Mass Transfer 55 (19-20): 5171-84. https://doi.org/10.1016/j.ijheatmasstransfer.2012.05.018.

[5] Pal Singh Bhinder, Amrit, Sandip Sarkar, and Amaresh Dalal. 2012. "Flow over and Forced Convection Heat Transfer around a Semi-Circular Cylinder at Incidence.” International Journal of Heat and Mass Transfer 55 (19-20): 5171-84. https://doi.org/10.1016/j.ijheatmasstransfer.2012.05.018.

[6] Bekele, Adisu, Manish Mishra, and Sushanta Dutta. 2014. "Performance Characteristics of Solar Air Heater with Surface Mounted Obstacles.

"Energy Conversion and Management 85: 603-11. https://doi.org/10.1016/j.enconman.2014.04.079. 
[7] Elsebay, M., I. Elbadawy, M. H. Shedid, and M. Fatouh. 2016. "Numerical Resizing Study of A12O3 and CuO Nanofluids in the Flat Tubes of a Radiator." Applied Mathematical Modelling 40 (13-14): 6437-50.

https://doi.org/10.1016/j.apm.2016.01.039.

[8] Rashidi, Saman, Masoud Bovand, Javad Abolfazli Esfahani, and Goodarz Ahmadi. 2016. "Discrete Particle Model for Convective AL2O3-Water Nanofluid around a Triangular Obstacle." Applied Thermal Engineering 100: 39-54. https://doi.org/10.1016/j.applthermaleng.2016.01.076.

[9] Oztop, Hakan F., Yasin Varol, and Dogan E. Alnak. 2009. "Control of Heat Transfer and Fluid Flow Using a Triangular Bar in Heated Blocks Located in a Channel." International Communications in Heat and Mass Transfer 36 (8): 878-85. https://doi.org/10.1016/j.icheatmasstransfer.2009.05.006.

[10] Teixeira, F. B., G. Lorenzini, M. R. Errera, L. A.O. Rocha, L. A. Isoldi, and E. D. dos Santos. 2018. "Constructal Design of Triangular Arrangements of Square Bluff Bodies under Forced Convective Turbulent Flows." International Journal of Heat and Mass Transfer 126: 521-35.

https://doi.org/10.1016/j.ijheatmasstransfer.2018.04.134.

[11] Derakhshandeh, J. F., and Md Mahbub Alam. 2019. "A Review of Bluff Body Wakes." Ocean Engineering 182 (May 2018): 475-88. https://doi.org/10.1016/j.oceaneng.2019.04.093.

[12] Sarac, Betul, Hussain Al-Madani, and Teoman Ayhan. 2011. "Heat Transfer from a Short Plate behind an Obstacle in Tandem." Energy Conversion and Management 52 (10): 3147-58. https://doi.org/10.1016/j.enconman.2011.04.019. 